\title{
On the Mechanism of Action of Dragmacidins I and J, Two New Representatives of a New Class of Protein Phosphatase 1 and 2A Inhibitors
}

\author{
Patricia G. Cruz, ${ }^{\dagger}$ Juan Fernando Martínez Leal, ${ }^{\dagger}$ Antonio Hernández Daranas, ${ }^{*}{ }^{\ddagger}$ (†) Marta Pérez, ${ }^{*}{ }^{\dagger}$ \\ and Carmen Cuevas ${ }^{\dagger}$
}

${ }^{\dagger}$ R\&D Area, PharmaMar, S.A., Avda. de los Reyes 1, Pol. Ind. La Mina, Colmenar Viejo, Madrid 28770, Spain

${ }^{\ddagger}$ Instituto de Productos Naturales y Agrobiología, Consejo Superior de Investigaciones Científicas (CSIC), La Laguna, Santa Cruz de Tenerife 38206, Spain

Supporting Information

\begin{abstract}
Two new brominated bis(indole) alkaloids, dragmacidins I (1) and J (2), showing low micromolar cytostatic activity, along with three known congeners were isolated from the Tanzanian sponge Dragmacidon sp. and their structures determined by the analysis of their NMR and MS data. From the study of their mechanism of action, it can be concluded that the mitotic arrest at metaphase in treated tumor cells, mediated by inhibition of PP1 and/or PP2A phosphatases is involved in the observed antiproliferative activity. Differences in their bioactivities were rationalized, and a plausible binding mode is proposed on the basis of computational simulations.
\end{abstract}

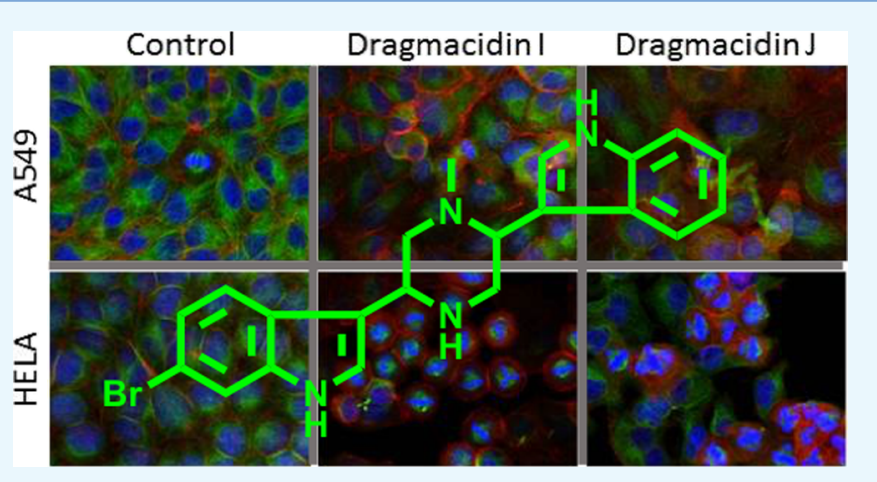

compounds, including their synthesis, ${ }^{15-17}$ have used the dragmacidin nomenclature, as we have used in this work.

\section{RESULTS AND DISCUSSION}

2.1. Isolation and Characterization. As a result of our continuing efforts to find antitumor compounds from marine organisms, we found that extracts obtained from the sponge Dragmacidon sp., collected off the coast of Tanzania at a depth of $80 \mathrm{~m}$, showed promising results in our bioassay-guided screening program. The organic extract $\left(\mathrm{CH}_{2} \mathrm{Cl}_{2} / \mathrm{CH}_{3} \mathrm{OH}, 1: 1\right)$ prepared from the frozen sample was fractionated using $\mathrm{C} 18$ reverse-phase flash liquid chromatography. Subsequent fractionation of the active portion using C18-HPLC was undertaken, yielding five structurally related bioactive compounds: two new metabolites, dragmacidin I (1) and dragmacidin J (2), along with the already-known dragmacidin A (3), ${ }^{6}$ dragmacidin B (4), ${ }^{6}$ and didebromodragmacidin (5), ${ }^{15,16}$ although it should be noted that the latter (5) has only been described as an intermediate in the total synthesis of $\mathbf{4}$ but not reported as a secondary metabolite isolated from a natural source (Figure 1).

2.2. Structural Elucidation. Dragmacidin I (1), isolated as a brown powder, showed a molecular formula of $\mathrm{C}_{21} \mathrm{H}_{21} \mathrm{BrN}_{4}$ based on its HRESITOFMS $(\mathrm{m} / z 409.1053$ and 411.1059 [M $+\mathrm{H}]^{+}$) and its ${ }^{1} \mathrm{H}$ and ${ }^{13} \mathrm{C}$ NMR spectra (Table 1). The

Received: November 13, 2017

Accepted: March 21, 2018

Published: April 3, 2018 


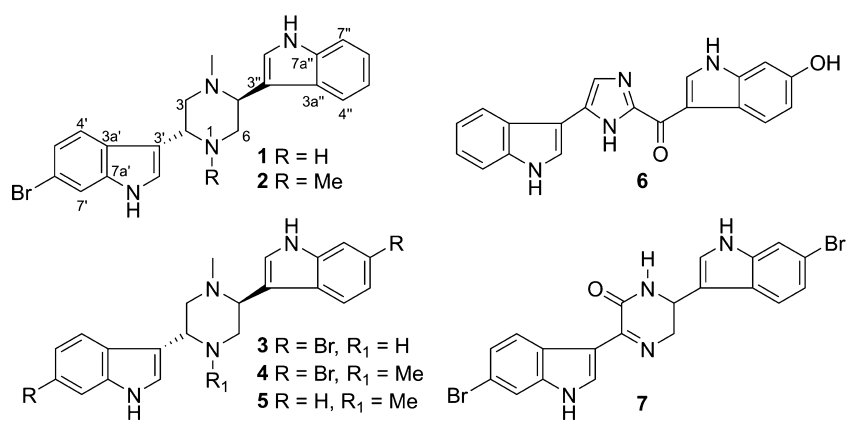

Figure 1. Structure of isolated dragmacidins $(\mathbf{1}-5)$, topsentin $(6)$, and hamacanthin A (7).

Table 1. ${ }^{1} \mathrm{H}$ and ${ }^{13} \mathrm{C}$ NMR Spectroscopic Data for 1 and 2 (Acetone- $d_{6}+$ TFA, 500/125 MHz)

\begin{tabular}{|c|c|c|c|c|}
\hline \multirow[b]{2}{*}{ Position } & \multicolumn{2}{|r|}{1} & \multicolumn{2}{|r|}{2} \\
\hline & $\delta_{\mathrm{C}}$, type & $\delta_{\mathrm{H}}$, mult. $(J$ in $\mathrm{Hz})$ & $\delta_{\mathrm{C}}$ type & $\delta_{\mathrm{H}}$, mult. $(J$ in $\mathrm{Hz})$ \\
\hline $\mathrm{N}-1 \mathrm{CH}_{3}$ & & & $\begin{array}{l}40.5 \\
\mathrm{CH}_{3}\end{array}$ & $2.88, \mathrm{~s}$ \\
\hline 2 & $\begin{array}{l}50.5 \\
\mathrm{CH}\end{array}$ & $5.91, \mathrm{dd}(11.9,3.3)$ & $\begin{array}{l}57.8 \\
\mathrm{CH}\end{array}$ & 5.79 , dd $(11.9,2.8)$ \\
\hline 3 & $\begin{array}{l}56.5 \\
\mathrm{CH}_{2}\end{array}$ & $\begin{array}{l}\text { (ax) } 4.42, \mathrm{dd}(13.3, \\
11.9)\end{array}$ & 56.7, & $\begin{array}{l}\text { (ax) } 4.50 \text {, dd (13.0, } \\
11.9)\end{array}$ \\
\hline & & $\begin{array}{l}\text { (eq) } 4.24 \text {, dd (13.3, } \\
3.3)\end{array}$ & & $\begin{array}{l}\text { (eq) } 4.20, \\
\text { overlapped }\end{array}$ \\
\hline $\mathrm{N}-4 \mathrm{CH}_{3}$ & $\begin{array}{l}40.7 \\
\mathrm{CH}_{3}\end{array}$ & $2.89, \mathrm{~s}$ & $\stackrel{40.5}{\mathrm{CH}_{3}}$ & $2.88, \mathrm{~s}$ \\
\hline 5 & $\begin{array}{l}57.2 \\
\mathrm{CH}\end{array}$ & $5.77, \mathrm{dd}(12.2,3.1)$ & 58.1, & 5.76 , dd $(12.0,3.2)$ \\
\hline 6 & $\begin{array}{l}47.9 \\
\mathrm{CH}_{2}\end{array}$ & $\begin{array}{l}\text { (ax) } 4.56, \mathrm{dd}(13.9 \text {, } \\
12.2)\end{array}$ & 56.8, & $\begin{array}{l}\text { (ax) } 4.46, \mathrm{dd}(13.1, \\
12.0)\end{array}$ \\
\hline & & $\begin{array}{l}\text { (eq) } 4.15 \text {, dd (13.9, } \\
3.1)\end{array}$ & & $\begin{array}{l}\text { (eq) } 4.20, \\
\text { overlapped }\end{array}$ \\
\hline $\mathrm{N}-1^{\prime}$ & & 10.90, br s & & 11.00 , br s \\
\hline $2^{\prime}$ & $\begin{array}{r}127.0, \\
\mathrm{CH}\end{array}$ & 7.97, d (1.8) & $\begin{array}{r}127.8 \\
\mathrm{CH}\end{array}$ & 7.94, d (1.8) \\
\hline $3^{\prime}$ & 107.9, C & & 106.1, C & \\
\hline $3 a^{\prime}$ & 125.7, C & & 126.6, C & \\
\hline $4^{\prime}$ & $\begin{array}{r}120.9 \\
\mathrm{CH}\end{array}$ & $7.79, \mathrm{dd}(8.5,0.7)$ & $\begin{array}{r}\text { 120.7 } \\
\mathrm{CH}\end{array}$ & $7.83, \mathrm{dd}(8.5,0.7)$ \\
\hline $5^{\prime}$ & $\begin{array}{r}124.0, \\
\mathrm{CH}\end{array}$ & $7.29, \mathrm{dd}(8.5,1.7)$ & $\begin{array}{r}124.4 \\
\mathrm{CH}\end{array}$ & 7.33, dd $(8.5,1.8)$ \\
\hline $6^{\prime}$ & 116.5, C & & 116.6, C & \\
\hline $7^{\prime}$ & $\begin{array}{r}\text { 115.7, } \\
\mathrm{CH}\end{array}$ & $7.74, \mathrm{dd}(1.7,0.7)$ & $\begin{array}{c}115.9 \\
\mathrm{CH}\end{array}$ & $7.78, \mathrm{dd}(1.8,0.7)$ \\
\hline $7 a^{\prime}$ & 137.8, C & & 137.8, C & \\
\hline $\mathrm{N}-1^{\prime \prime}$ & & 10.90, br s & & 11.90 , br s \\
\hline $2^{\prime \prime}$ & $\begin{array}{r}127.0, \\
\mathrm{CH}\end{array}$ & 7.96, d (2.4) & $\begin{array}{r}\text { 126.6, } \\
\mathrm{CH}\end{array}$ & $7.89, \mathrm{~d}(2.7)$ \\
\hline $3^{\prime \prime}$ & 105.6, C & & 105.5, C & \\
\hline $3 a^{\prime \prime}$ & $127.9, \mathrm{C}$ & & 127.6, C & \\
\hline $4^{\prime \prime}$ & $\begin{array}{r}118.9 \\
\mathrm{CH}\end{array}$ & $7.87, \mathrm{dd}(7.9,1.0)$ & $\begin{array}{r}118.9 \\
\mathrm{CH}\end{array}$ & 7.86, dd $(8.1,1.0)$ \\
\hline $5^{\prime \prime}$ & $\begin{array}{r}121.4, \\
\mathrm{CH}\end{array}$ & $\begin{array}{l}\text { 7.20, ddd (7.9, 7.0, } \\
1.0)\end{array}$ & $\begin{array}{r}121.4 \\
\mathrm{CH}\end{array}$ & $\begin{array}{l}\text { 7.20, ddd (7.5, 7.1, } \\
1.0)\end{array}$ \\
\hline $6^{\prime \prime}$ & $\begin{array}{r}123.6, \\
\mathrm{CH}\end{array}$ & $\begin{array}{l}\text { 7.26, ddd (8.1, 7.0, } \\
1.0)\end{array}$ & $\begin{array}{r}\text { 123.6, } \\
\mathrm{CH}\end{array}$ & $\begin{array}{l}\text { 7.26, ddd (7.5, 7.1, } \\
1.0)\end{array}$ \\
\hline $7^{\prime \prime}$ & $\begin{array}{r}\text { 113.0, } \\
\mathrm{CH}\end{array}$ & $7.56, \mathrm{dd}(8.1,1.0)$ & $\begin{array}{r}\text { 113.0, } \\
\mathrm{CH}\end{array}$ & 7.56, dd $(8.1,1.0)$ \\
\hline $7 a^{\prime \prime}$ & 137.0, C & & 137.0, C & \\
\hline
\end{tabular}

observation of peaks at $m / z 409$ and 411 in a 1:1 ratio indicated the existence of a bromine atom within the molecule. Analysis of the ${ }^{1} \mathrm{H},{ }^{13} \mathrm{C} \mathrm{NMR}$, and gHSQC spectra showed the presence of 21 carbon atoms that could be assigned as nine $\mathrm{sp}^{2}$ methines, two $\mathrm{sp}^{3}$ methylenes, two $\mathrm{sp}^{3}$ methines, one methyl group, and seven nonprotonated carbons. Analysis of gCOSY and gHMBC spectra allowed the assembly of the planar structure of the molecule (Figure 2). Thus, the COSY cross-peak between $\mathrm{H}^{\prime}$

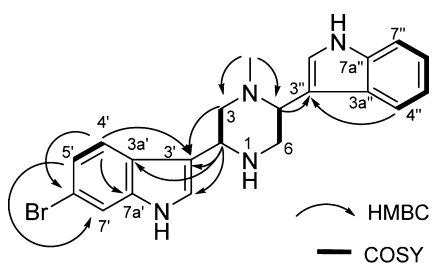

Figure 2. Selected 2D NMR correlations observed for dragmacidin I (1).

and $\mathrm{H}^{\prime}$ ' together with the observed gHMBC correlations between $\mathrm{H}^{\prime}$ and $\mathrm{C}^{\prime}, \mathrm{C}^{\prime}$, and $\mathrm{C}^{\prime} \mathrm{a}^{\prime}$, between $\mathrm{H}^{\prime}$ and $\mathrm{C}^{\prime}$ and $\mathrm{C} 3 \mathrm{a}^{\prime}$, and between $\mathrm{H} 2^{\prime}$ and $\mathrm{C} 3 \mathrm{a}^{\prime}$ and $\mathrm{C} 7 \mathrm{a}^{\prime}$ indicated the presence of a 6-bromoindol-3-yl moiety. The $\mathrm{H} 4^{\prime \prime}-\mathrm{H} 5^{\prime \prime}-$ $\mathrm{H} 6 "-\mathrm{H} 7$ " spin system was established from gCOSY crosspeaks, which in combination with gHMBC correlations between $\mathrm{H}^{\prime \prime}$ and $\mathrm{C} 7 \mathrm{a}^{\prime \prime}$, between $\mathrm{H} 7{ }^{\prime \prime}$ and $\mathrm{C} 3 \mathrm{a}^{\prime \prime}$, and between $\mathrm{H} 2$ " and $\mathrm{C}^{\prime \prime}, \mathrm{C} 3 \mathrm{a}^{\prime \prime}$, and C7a" indicated the presence of an indol-3-yl moiety. The third fragment was established to be an $\mathrm{N}$-methyl piperazine ring through gCOSY correlations between $\mathrm{H} 2-\mathrm{H} 3$ and $\mathrm{H} 5-\mathrm{H} 6$, in combination with three-bond correlations between the methyl group at $\delta_{\mathrm{H}} 2.89$ and C3 and $\mathrm{C} 5$. Both indolyl moieties were joined to the piperazine ring by the observed gHMBC correlations between $\mathrm{H} 2$ and $\mathrm{C}^{\prime}$, $\mathrm{C}^{\prime}$, and $\mathrm{C}^{\prime} \mathrm{a}^{\prime}$, together with the correlation between $\mathrm{H} 5$ and $\mathrm{C} 3^{\prime \prime}$.

The stereochemical relationships within this molecule were solved on the basis of the observed large coupling constants between $\mathrm{H} 5-\mathrm{H} 6_{\mathrm{ax}}\left({ }^{3} J_{\mathrm{H} 5-\mathrm{H} 6_{\mathrm{ax}}}=12.8 \mathrm{~Hz}\right)$ and $\mathrm{H} 2-\mathrm{H} 3_{\mathrm{ax}}$ $\left({ }^{3} \mathrm{~J}_{\mathrm{H} 2-\mathrm{H} 3_{\mathrm{ax}}}=12.8 \mathrm{~Hz}\right)$, characteristic of antiperiplanar-orientated protons along with the dipolar correlations observed in the ROESY experiment between $\mathrm{H} 3_{\mathrm{ax}}$ and $\mathrm{H} 5_{\mathrm{ax}}$ as well as between $\mathrm{H} 2_{\mathrm{ax}}$ and $\mathrm{H}_{\mathrm{ax}}$. These data set the relative orientation of $\mathrm{H} 2$ and $\mathrm{H} 5$ as trans-diaxial, indicating that both indolyl residues are in equatorial positions. Further analysis of the ROESY experiment showed clear dipolar correlations between the aromatic protons $\mathrm{H} 4^{\prime}$ and $\mathrm{H}^{\prime \prime}$ with the piperazine protons $\mathrm{H} 2$ and $\mathrm{H} 5$, respectively. Moreover, the indole proton $\mathrm{H}^{\prime}$ cross-correlated with $\mathrm{H} 3_{\mathrm{ax}}$ as did the corresponding $\mathrm{H} 2^{\prime \prime}$ with $\mathrm{H} 6_{\mathrm{ax}}$. From this information, it appears that both indole rings adopt a perpendicular orientation relative to the main plane of the piperazine moiety of $\mathbf{1}$, as depicted in Figure 3.

Dragmacidin J (2) was isolated as a brown powder, with a molecular formula of $\mathrm{C}_{22} \mathrm{H}_{23} \mathrm{BrN}_{4}$ based on its HRESITOFMS $\left(\mathrm{m} / z 423.1148\right.$ and $\left.425.1145[\mathrm{M}+\mathrm{H}]^{+}\right)$, suggesting that, compared to $\mathbf{1}$, compound $\mathbf{2}$ bears an additional methyl group.

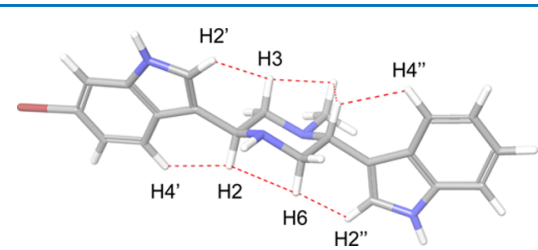

Figure 3. Three-dimensional molecular model of dragmacidin I (1). Dipolar interactions, as detected by the ROESY experiment, are depicted as red dashed lines. 
This observation was supported by the analysis of $1 \mathrm{D}$ and $2 \mathrm{D}$ NMR experiments (see Table S1 in the Supporting Information) that clearly showed the presence of a new methyl group at $\delta_{\mathrm{H}} / \delta_{\mathrm{C}} 2.88 / 40.5$ and allowed the assignment of all ${ }^{1} \mathrm{H}$ and ${ }^{13} \mathrm{C}$ signals, where the most notable changes were observed in the chemical shifts of $\mathrm{C} 2, \mathrm{C} 6$, and $\mathrm{C}^{\prime}$. The relative orientation of the substituents at $\mathrm{C} 2$ and $\mathrm{C} 5$ was established as trans-equatorial $\left({ }^{3} J_{\mathrm{H} 5-\mathrm{H}_{\mathrm{ax}}}=12.8 \mathrm{~Hz}\right.$ and $\left.{ }^{3} J_{\mathrm{H} 2-\mathrm{H}_{\mathrm{ax}}}=12.8 \mathrm{~Hz}\right)$, as proposed for $\mathbf{1}$.

Dragmacidin A (3), dragmacidin B (4), and didebromodragmacidin (5) were studied and their HRESITOFMS as well as their NMR data were compared with those reported in the literature. Complete matches were found for all three compounds, thereby confirming their structures.

The absolute configuration of the new dragmacidins I (1) and $J(2)$ is proposed to be $(2 R, 5 S)$ on the basis of their measured optical rotation values. Thus, the positive specific rotations measured in methanol for $1(+4.7, c 0.1)$ and 2 $(+13.0, c 0.1)$ are very close to that reported for dragmacidin A $(+4, c 0.2)$ prepared by enantioselective total synthesis, ${ }^{14}$ clearly suggests an identical absolute configuration for all of them.

2.3. Biological Activity. It has been reported that some bis(indole) compounds show important biological activities. ${ }^{10-13}$ In particular, dragmacidins $\mathrm{E}$ and $\mathrm{D}$ were reported as inhibitors of serine/threonine PPs, but no experimental details were published by the authors. ${ }^{12}$ Therefore, all of the isolated compounds (1-5) were evaluated to assess their antiproliferative activity toward three different human cancer cell lines: lung (A549), colon (HT29), and breast (MDA-MB231). Three molecules (1-3) revealed a significant bioactivity against all of the tested cell lines (Table 2). Interestingly,

Table 2. Cytostatic Activity $(\mu \mathrm{M})$ of Compounds 1-5 against Three Human Tumor Cell Lines

\begin{tabular}{cccc} 
& \multicolumn{3}{c}{ cell lines } \\
\cline { 2 - 4 } $\mathbf{1}$ & A549 & HT29 & MDA-MB-231 \\
$\mathbf{2}$ & 2.7 & 3.3 & 4.7 \\
$\mathbf{3}$ & 4.7 & 4.8 & 7.5 \\
$\mathbf{4}$ & 3.1 & 3.3 & 3.8 \\
$\mathbf{5}$ & 20.3 & 19.3 & 28.0 \\
\hline
\end{tabular}

nonsymmetric compounds 1,2 , and 3 proved to be clearly more active than their two symmetrical partners $\mathbf{4}$ and $\mathbf{5}$. Although it has been described that molecular symmetry is an important structural property in some cytotoxic compounds, ${ }^{18}$ this is a counterexample where in vitro activity correlates with the spatial nonsymmetrical distribution more than with the degree of substitution.

To get insights into the mechanism of action of the active molecules, both A549 (lung) and HeLa (cervix) carcinoma cells were treated with compounds 1-4 at different concentrations, and their actin and tubulin cytoskeletons were examined by immunofluorescence with appropriate primary and secondary antibodies. HeLa cells were used at this stage because of their higher sensitivity to antimitotic agents, therefore being more appropriate for microscopy studies. These studies revealed that after treatment for $24 \mathrm{~h}$ at $10 \mu \mathrm{M}$, compounds 1-3 induced a mitotic arrest in metaphase in HeLa cells that was independent of the disorganization of the tubulin cytoskeleton because at this concentration, an important portion of the cells remained phenotypically normal, and their microtubules were appropriately polymerized (Figure 4). Furthermore, A549 cells treated with compounds 1-4 at an identical concentration $(10 \mu \mathrm{M})$ did not show any effect on their cytoskeleton and were not multinucleated as should be the case after treatment with tubulin-binding agents. Confirmation of the previous observations about the mitotic arrest induced by this class of compounds was obtained by analyzing the cell cycle of the treated tumor cells by flow cytometry. Thus, after $6 \mathrm{~h}$ of treatment with $10 \mu \mathrm{M}$ of 4 , a clear $\mathrm{G} 2 / \mathrm{M}$ arrest was observed, both in A549 and HeLa cells (see Figure S1 in the Supporting Information). Indeed, the ratio of A549 cells in G2/M increased from $11 \%$ in the control to $30 \%$ after treatment with 4, whereas in HeLa cells, the ratio moved from 15 to $48 \%$ (see Table S3 in the Supporting Information).

Next, we examined whether the observed cell cycle arrest in metaphase was because of the inhibition of a protein kinase involved in mitosis. To this end, dragmacidin A (3) was tested against a full panel of kinases including 28 cyclin-dependent kinases; 11 serine/threonine-protein kinases NEK, PLK, and BUB1; and aurora A, B, and C kinases (a detailed list is included in the Supporting Information). However, none of them was significantly inhibited at the tested concentration (10 $\mu \mathrm{M})$, indicating that the mechanism of action of these compounds does not implicate the inhibition of these proteins. We then analyzed whether dragmacidins were inhibiting phosphatases, the kinases' counteracting partners that are also essential for the dynamics of cell cycle. We treated HeLa cells with $10 \mu \mathrm{M}$ of compounds $1-4$ for 1,6 , and $24 \mathrm{~h}$, monitoring the phosphorylation status of the retinoblastoma protein (pRB), an essential cell cycle controller which is regulated through dephosphorylation by PPs, PP1 and PP2A. As a result, we observed a continuous increment of the pRB phosphorylation status in HeLa cells after 1, 6, and $24 \mathrm{~h}$ of exposure to dragmacidins 1-4, showing that this family of compounds effectively inhibits PP1 and/or PP2A phosphatases. Similar

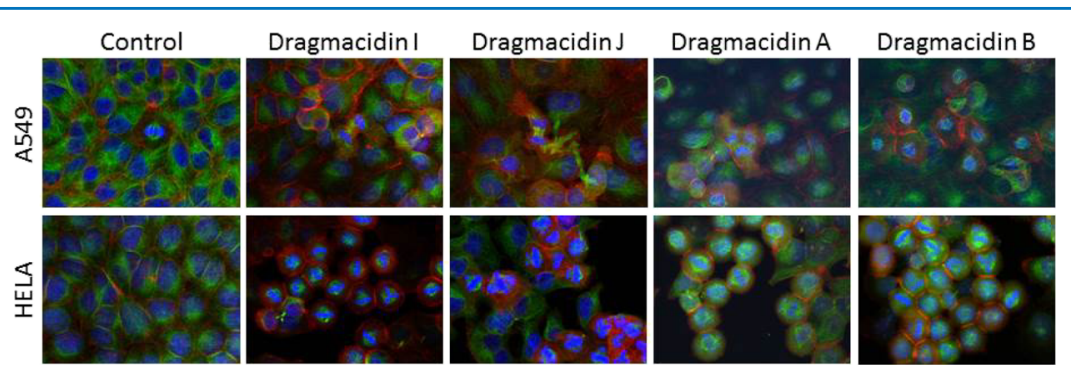

Figure 4. Immunofluorescence photographs showing the effects of dragmacidins in tumor cell cultures. Actin is shown in red, tubulin in green, and DNA (stained with Hoechst 33342) in blue. 

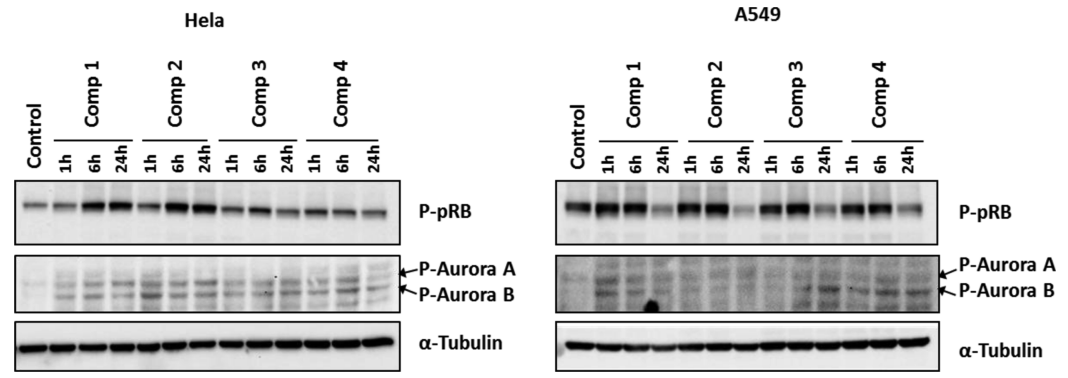

Figure 5. Western blot assays undertaken on HeLa (left) and A549 (right) cells extract to monitor the phosphorylation status of the pRB (P-pRB).

results were observed in A549 cells where the hyperphosphorylation of pRB increased after 1 and $6 \mathrm{~h}$ of incubation, but subsequently turned down, resulting in a hypophosphorylated protein after $24 \mathrm{~h}$. We also analyzed the phosphorylation status of AURKA and AURKB, both kinases being essential in the transition from metaphase to anaphase during mitosis and both of them targets of PPs, PP1 and PP2A. Again, we could see an increase in the phosphorylation of both kinases, clear after $1 \mathrm{~h}$ of treatment with the compounds and remaining high after $24 \mathrm{~h}$ of treatment (Figure 5).

Therefore, our conclusion was that mitotic arrest at metaphase in treated tumor cells mediated by inhibition of PP1 and/or PP2A phosphatases is involved in-if not responsible for-the observed antiproliferative activity of dragmacidins 1-4. This statement was corroborated by evaluating compounds $\mathbf{1 - 5}$ in vitro to test their inhibition of the PP1 phosphatase. Residual activities of $48.7 \pm 6.0 \%, 45.3 \pm$ $4.2 \%, 54.3 \pm 5.5 \%, 102.3 \pm 13.0 \%$, and $101.0 \pm 4.4 \%$ were, respectively, obtained after incubation of the enzyme with a 10 $\mu \mathrm{M}$ concentration of $\mathbf{1 - 5}$ in our assays, indicating that compounds 1-3 have an $\mathrm{IC}_{50}$ value close to $10 \mu \mathrm{M}$, whereas 4-5 did not show significant inhibition at the tested concentration. These values are on the same order of magnitude as those obtained from the cytotoxicity assays.

Dragmacidins do not share a common structural characteristic of most PP1 and PP2A inhibitors, that is, the presence of a negatively charged residue, generally a phosphate or a carboxylic acid, to mimic the phosphate group that these proteins hydrolyze. ${ }^{19,20}$ In addition, despite compounds 1-5 representing only a small series of structural variations, their structure-activity relationships turned out to be intriguing. The loss of in vitro activity observed in $\mathbf{4}$ and $\mathbf{5}$ is difficult to understand, as their structural variations are small compared to 1-3. Thus, we first looked at potential differences in $\mathrm{p} K_{\mathrm{a}}$ values among $\mathbf{1 - 5}$ as a possible explanation. Dragmacidins are weak bases and in consequence, variations in their neutral/charged ratios may have an impact on their ability to cross cell membranes. Therefore, $\mathrm{p} K_{\mathrm{a}}$ values for each compound (1-5) were calculated using a combination of molecular mechanics (MM) and DFT computational methods, as implemented in the jaguar $\mathrm{p} K_{\mathrm{a}}$ software ${ }^{21}$ (Table 3 ). Smaller $\mathrm{p} K_{\mathrm{a}}$ values were obtained in our calculations for the piperazine moiety of compounds 1-3 and therefore there would be a smaller ionized fraction of them under the assayed conditions (i.e., at $\mathrm{pH}=7.4$, $83 \%$ ionization for a $\mathrm{p} K_{\mathrm{a}}=8.1$ in 5 vs $64 \%$ for $\mathrm{p} K_{\mathrm{a}}=7.5$ in 3 ). Considering that the neutral form of a drug is more lipidsoluble, this would result in a better diffusion of 1-3 into the cell. Although differences between the predicted $\mathrm{p} K_{\mathrm{a}}$ values are small, results become more reliable because the differences between predicted values are calculated more accurately than
Table 3. $\mathrm{p} K_{\mathrm{a}}$ Values Predicted with DFT Computational Methods on Compounds 1-5

\begin{tabular}{ccccc} 
& \multicolumn{4}{c}{ atom position } \\
\cline { 2 - 5 } $\mathbf{1}$ & $\mathrm{N}-1$ & $\mathrm{~N}-2$ & $\mathrm{~N}-1^{\prime}$ & $\mathrm{N}-1^{\prime \prime}$ \\
$\mathbf{2}$ & 7.6 & 8.1 & -4.0 & -3.2 \\
$\mathbf{3}$ & 7.9 & 8.0 & -4.2 & -3.2 \\
$\mathbf{4}$ & 7.5 & 7.9 & -4.1 & -4.0 \\
$\mathbf{5}$ & 8.1 & 8.1 & -3.9 & -3.8 \\
\hline
\end{tabular}

absolute $\mathrm{p} K_{\mathrm{a}}$ values themselves because of the cancellation of systematic errors. ${ }^{21}$ This calculated physicochemical outcome is in accordance with the experimentally measured bioactivities and may provide a rationale for the observed variations.

Next, in an attempt to understand the basis of the observed differences in bioactivity, simulations of docking 1-5 into the binding pocket of PP1 were performed. ${ }^{22-25}$ Metalloproteins, such as PP1 that includes two manganese atoms on its binding pocket, are challenging systems to model because of the limitation of currently available force fields treating transition metal atoms. In this case, for our calculations, we decided to keep one crystallographic water molecule directly coordinated with both metal ions. ${ }^{26,27}$ This was because after inspection of PP1 crystallographic structures in complex with different inhibitors, it turned out that this water molecule was a common feature of all of them..$^{22-25}$ To predict protein-ligand binding, we used a three-step procedure: first, electrostatic charges were calculated for all protein residues located at less than $3 \mathrm{~A}$ of the metal ions using DFT calculations at the B3LYP/6-31G** level. ${ }^{28}$ These charges were then used to perform a quantum mechanics/MM (QM/MM) docking. This step improves the treatment of partial charges induced by the receptor on the ligands, obtaining them from QM calculations. ${ }^{29}$ Finally, the 10 best binding poses obtained from QM/ MM docking of each ligand were evaluated using MMgeneralized Born surface area (GBSA) calculations. ${ }^{30}$ The last calculations were used to estimate relative binding affinities, and although the absolute values calculated are not necessarily in agreement with experimental binding affinities, the relative ranking of the ligands is expected to agree reasonably well, particularly in the case of congeneric series, as it is the case. Taking into account that the previously calculated $\mathrm{p} K_{\mathrm{a}}$ values were close to the physiological $\mathrm{pH}$, calculations were performed using both ionized and nonionized states for all ligands.

Our simulations resulted in two general binding trends. One set of poses filling the hydrophobic groove and a second set of solutions filling the acidic groove of the PP1 binding site. In most cases, the conformation of the bound ligand remained similar to that of the free status; this is with both indole rings 
oriented in a plane perpendicular to the central piperazine ring. As we expected, because of the absence of negatively charge groups in $\mathbf{1 - 5}$, few simulations resulted in ligands directly interacting with the metals in the active site. Thus, $\mathbf{1}$, the ligand with the best bioactivity, showed the most negative interaction energy $\left(\Delta G_{\text {binding }}=-42.6 \mathrm{kcal} / \mathrm{mol}\right)$ on its nonprotonated state bound into the hydrophobic groove. An analysis of its binding interactions indicated that $\pi-\pi$ stacking interactions as well as $\mathrm{H}$-bonds between both indole rings and the protein stabilizes the complex of 1 with PP1 (Figure 6). On the other hand,
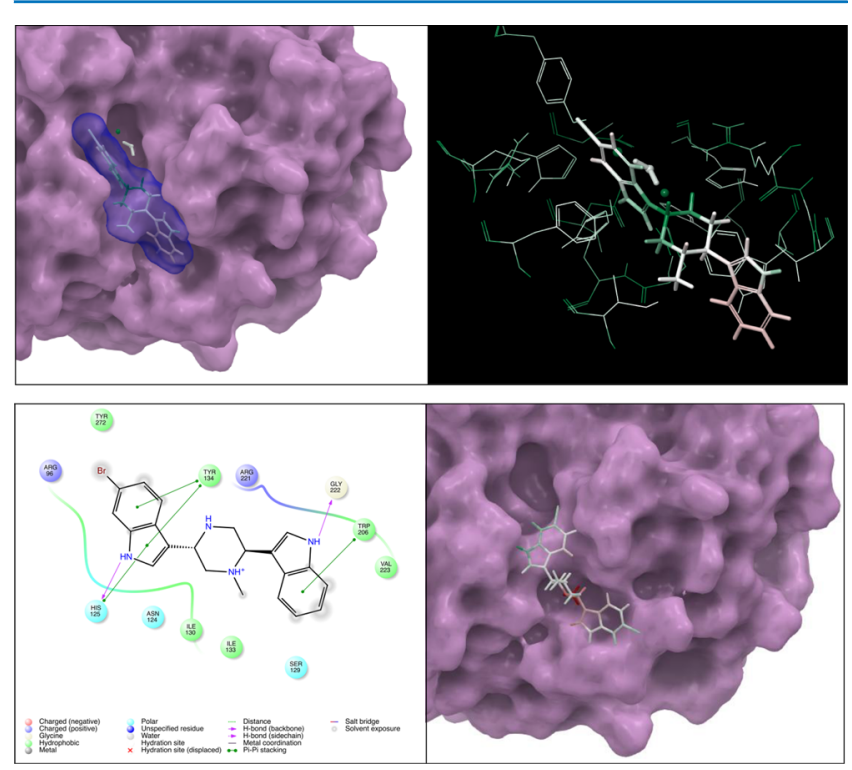

Figure 6. Binding modes of compounds 1 (upper line and bottom left) and 4 (bottom right) into the hydrophobic groove of the active site of PP1, as obtained after MM-GBSA simulations. The protein is represented by a van der Waals surface. The ligands are color-coded according to the sum of all computed energy components with green and red indicating favorable and negative contributions, respectively.

ligands 2 and 3 displayed their best binding affinities on its protonated form bound into the hydrophobic groove. However, while $\mathbf{2}$ seems to keep the same position as $\mathbf{1}$ into the binding site, ligand 3 turned out to be slightly shifted down into the hydrophobic groove, possibly because of its larger size as it includes an additional bromine atom, resulting in $\mathbf{1}$ in each indole moiety now. Equally, 4 showed its best affinity on its protonated state, forming a complex almost superimposable with that obtained for 3 . However, according to our results, the new $N$-methyl group of 4 shows unfavorable electrostatic interactions mainly with the indolic NH of Trp 206, something that could explain its lower bioactivity. Finally, didebromodragmacidin 5, the ligand with the lowest bioactivity, was the only one that showed binding poses exclusively within the acidic groove of the PP1 binding site.

\section{CONCLUSIONS}

Two new congeners of the dragmacidin family of alkaloids have been isolated from the marine sponge Dragmacidon sp. together with the other related metabolites. These molecules were tested in antiproliferative activity assays resulting in low micromolar activities. Their mechanism of action was investigated through different molecular biology experiments that indicated that these molecules act via inhibition of Ser-Thr PPs. Moreover, according to our simulations, dragmacidins bind PP1 by filling the hydrophobic groove of the binding site, not directly interacting with the metal atoms of the protein but blocking the access of target protein phosphate groups into the catalytic site in a way that may represent a new paradigm to inhibit Ser-Thr PPs type 1 and possibly other analogous phosphatases such as PP2A.

\section{METHODS}

4.1. General. Optical rotations were measured on a Jasco P1020 polarimeter. UV spectra were obtained using an Agilent 1100 DAD. IR spectra were acquired on a PerkinElmer Spectrum 100 FT-IR spectrometer with ATR sampling. NMR spectra were recorded on a Varian "Unity 500" spectrometer operating at $500 / 125 \mathrm{MHz}\left({ }^{1} \mathrm{H} /{ }^{13} \mathrm{C}\right)$, approximately. Chemical shifts were reported in parts per million using residual acetone$d_{6}$ signal $\left(\delta_{\mathrm{H}} 2.05\right.$ and $\left.\delta_{\mathrm{C}} 29.84\right)$ as the internal reference. HRESITOFMS spectra were acquired on an Agilent 6230 TOF LC/MS chromatograph spectrometer. HPLC purifications were performed on an Agilent 1100 HPLC equipped with a Gilson FC204 fraction collector and a DAD G1315B Agilent detector.

4.2. Sponge Material. The sponge Dragmacidon sp. was collected in Kashani Island ( $039^{\circ} 36^{\prime} 937^{\prime \prime}$ E, $\left.05^{\circ} 08^{\prime} 010^{\prime \prime} \mathrm{S}\right)$, Tanzania, in February 2010, by autonomous diving using a closed-circuit rebreather at a depth of $-80 \mathrm{~m}$. The sample was immediately frozen at $-20{ }^{\circ} \mathrm{C}$. A voucher specimen was identified by Dr. Santiago Bueno Horcajadas and deposited at PharmaMar (ORMA086310).

4.3. Extraction and Isolation. The frozen organism ( 125 g) was triturated and extracted 3 times using $500 \mathrm{~mL}$ of a $1: 1$ mixture of $\mathrm{CH}_{2} \mathrm{Cl}_{2} / \mathrm{CH}_{3} \mathrm{OH}$. The combined extracts were concentrated to give a dry brownish crude $(12.3 \mathrm{~g})$, which was subjected to vacuum liquid chromatography on Polygoprep RP18 stationary phase with a stepped gradient started with $\mathrm{H}_{2} \mathrm{O}$, subsequently followed by $\mathrm{CH}_{3} \mathrm{OH}$ and $\mathrm{CH}_{3} \mathrm{OH} / \mathrm{CH}_{2} \mathrm{Cl}_{2}$ (50:50). The fraction eluted with $\mathrm{CH}_{3} \mathrm{OH}$ was further purified by HPLC using a Sunfire Prep C18 column $(5 \mu \mathrm{m} ; 10 \times 150$ $\mathrm{mm}$; Waters), with a gradient of $\mathrm{CH}_{3} \mathrm{CN} / \mathrm{H}_{2} \mathrm{O}(+0.04 \%$ TFA) starting from $20 \% \mathrm{H}_{2} \mathrm{O}$ that rose to $50 \%$ in 20 min (flow rate 3 $\mathrm{mL} / \mathrm{min}$ and $\mathrm{UV}$ detection at $254 \mathrm{~nm})$. This procedure yielded compounds $1\left(6.8 \mathrm{mg}, t_{\mathrm{R}}=7.9 \mathrm{~min}\right), 2\left(11.7 \mathrm{mg}, t_{\mathrm{R}}=10.7\right), 3$ $\left(2.5 \mathrm{mg}, t_{\mathrm{R}}=12.0 \mathrm{~min}\right), 4\left(2.4 \mathrm{mg}, t_{\mathrm{R}}=15.3 \mathrm{~min}\right)$, and $5(0.7$ $\left.\mathrm{mg}, t_{\mathrm{R}}=6.6 \mathrm{~min}\right)$.

4.4. Spectral Data. 4.4.1. Compound 1. Brown powder; $[\alpha]_{\mathrm{D}}^{25}+4.7\left(c\right.$ 0.1, $\left.\mathrm{CH}_{3} \mathrm{OH}\right)$; UV $\lambda_{\max } 216,280 \mathrm{~nm}\left(\mathrm{CH}_{3} \mathrm{OH}\right)$; IR (neat) $\nu_{\max }: 3513,3314,1674,1200,1138 \mathrm{~cm}^{-1} ;{ }^{1} \mathrm{H}$ NMR $(500 \mathrm{MHz})$ and ${ }^{13} \mathrm{C}$ NMR (125 MHz), see Table 1; (+)-HRESIMS $m / z: 409.1053$ and $411.1059[\mathrm{M}+\mathrm{H}]^{+}$ (calcd for $\mathrm{C}_{21} \mathrm{H}_{22} \mathrm{BrN}_{4}, 409.1028$ and 411.1007).

4.4.2. Compound 2. Brown powder; $[\alpha]_{\mathrm{D}}^{25}+13.0$ (c 0.1 , $\left.\mathrm{CH}_{3} \mathrm{OH}\right)$; UV $\lambda_{\max } 215,280 \mathrm{~nm}\left(\mathrm{CH}_{3} \mathrm{OH}\right)$; IR (neat) $\nu_{\max }$ : 3547, 3246, 1673, 1455, 1201 and $1137 \mathrm{~cm}^{-1}$; ${ }^{1} \mathrm{H}$ NMR (500 $\mathrm{MHz})$ and ${ }^{13} \mathrm{C}$ NMR (125 MHz), see Table 1; (+)-HRESIMS $m / z: 423.1203$ and $425.1145[\mathrm{M}+\mathrm{H}]^{+}$(calcd for $\mathrm{C}_{22} \mathrm{H}_{24} \mathrm{BrN}_{4}$, 423.1184 and 425.1164).

4.5. Biological Evaluation. 4.5.1. Antiproliferative Assays. A549 (ATCC CCL-185) lung carcinoma, HT29 (ATCC HTB-38) colon adenocarcinoma, MDA-MB-231 (ATCC HTB26) breast adenocarcinoma, and HeLa (ATCC CRM-CCL-2) cervix adenocarcinoma cells were obtained from the American Type Culture Collection (ATCC) and were cultured at $37{ }^{\circ} \mathrm{C}$ and $5 \% \mathrm{CO}_{2}$ in Dulbecco's modified Eagle medium supplemented with $10 \%$ fetal bovine serum, $1 \%$ penicillin and 
streptomycin, and $2 \mathrm{mM}$ L-glutamine. Cell cultures were always kept at the low-passage stage.

A colorimetric assay with sulforhodamine B (SRB) was used to determine the antiproliferative activity of the compounds. Briefly, cells were seeded in 96-well microtiter plates and allowed to stand for $24 \mathrm{~h}$ in drug-free medium before treatment with vehicle alone or a range of 10 serial half dilutions starting from $20 \mu \mathrm{M}$ of the compounds for $72 \mathrm{~h}$. For quantification, cells were washed twice with phosphate-buffered saline (PBS), fixed for $15 \mathrm{~min}$ in $1 \%$ glutaraldehyde solution, rinsed twice with PBS, stained in $0.4 \%$ SRB- $1 \%$ acetic acid solution for 30 min, rinsed several times with $1 \%$ acetic acid solution, and airdried. SRB was then extracted with $10 \mathrm{mM}$ Trizma base solution and the optical density measured at $490 \mathrm{~nm}$ in a POLARstar Omega microplate multilabel reader (BMG Labtech, Ortenberg, Germany). All evaluations were performed in triplicate, and the resulting data were fitted by nonlinear regression to a four-parameter logistic curve with Prism v5.0 software (GraphPad Software, La Jolla, CA, USA), following the algorithm developed by the American National Cancer Institute $(\mathrm{NCI}){ }^{1}$ This algorithm calculates the $\mathrm{GI}_{50}$ value, the compound concentration that produces $50 \%$ of the cell growth inhibition as compared to control cultures, a convenient measure of the activity of cytostatic compounds.

4.5.2. Immunofluorescence. Cells were treated with the appropriate concentration of the compounds for $24 \mathrm{~h}$, then fixed ( $4 \%$ paraformaldehyde), permeabilized ( $0.5 \%$ Triton X$100)$, and incubated with appropriate primary and secondary fluorescence-conjugated antibodies, following the manufacturer's instructions. Preparations were counterstained with Hoechst 33342, labeling DNA, and mounted with Mowiol mounting medium. Pictures were taken with a Zeiss Axiovert 200M microscope equipped with a $63 \times$ oil-immersion objective, an Axiocam HRm digital camera, and an Apotome1 structured illumination system (Zeiss, Jena, Germany).

4.5.3. Western Blot. Cell protein extracts were prepared following standard procedures in RIPA buffer in the presence of protease inhibitors (Complete, Roche Diagnostics) and phosphatase inhibitors (PhosStop, Roche Diagnostics). After quantification with BCATM Protein Assay Kit (Thermo Scientific, Waltham, MA, USA), 15-25 $\mu \mathrm{g}$ of protein were separated by SDS-PAGE and transferred to PVDF membranes (Immobilon-P, Millipore, Billerica, MA, USA). After using appropriate primary and secondary antibodies, blots were developed by a peroxidase reaction using the ECL detection system (Amersham-G.E. Healthcare, Little Chalfont, UK) with a ChemiDoc imaging system (Bio-Rad).

4.5.4. Cell Cycle Analysis by Flow Cytometry. Cells were treated with $10 \mu \mathrm{M}$ of the assayed compounds for $6 \mathrm{~h}$ and subsequently washed with PBS and fixed with $70 \%$ cold ethanol. Cells were then treated with RNAse I and stained with $50 \mu \mathrm{g} / \mathrm{mL}$ propidium iodide. Samples were analyzed with a BD Accuri-6 flow cytometer (Becton and Dickinson, Franklin Lakes, NJ, USA) and the FlowJo v10.1 cytometry analysis software (Tree Star, Ashland, OR, USA).

4.5.5. PP Inhibition Assays. Ser-Thr PP-1 catalytic subunit (PP1c) was purchased from Sigma-Aldrich (P7937). The EnzCheck Phosphatase Assay Kit from Molecular Probes was used to monitor the phosphatase activity. This kit uses 6,8difluoro-4-methylumbelliferyl phosphate (DiFMUP) as a substrate for the enzyme. Assays were performed at $25{ }^{\circ} \mathrm{C}$ using 0.2 units of protein and $10 \mu \mathrm{M}$ of the tested compounds (1-5) in a volume of $100 \mu \mathrm{L}$ of $\mathrm{pH} 7.4$ buffer-containing 250
$\mathrm{mM} \mathrm{NaCl}, 50 \mathrm{mM}$ imidazole, $2 \mathrm{mM}$ DTT, $1 \mathrm{mM}$ EDTA, 2 $\mathrm{mM} \mathrm{MnCl} 2,0.025 \%$ TWEEN 20, and 20\% (v/v) glycerol. DiFMUP $(5 \mu \mathrm{M})$ was used as a substrate, essentially following the method provided with the reactive. The hydrolysis reaction was monitored by fluorescence spectroscopy at $\lambda_{\mathrm{ex}}$ of $360 \mathrm{nM}$ and $\lambda_{\mathrm{em}}$ of $460 \mathrm{nM}$. Assays were performed in triplicate, and errors are described as standard deviation from the average.

4.6. Computational Chemistry. 4.6.1. Conformational Searches. Molecular modeling calculations were carried out using Macromodel software. ${ }^{31}$ Conformational searches of dragmacidins 1-5 were undertaken using 1000 steps of a hybrid method that included torsional and low-mode sampling. All searches were carried out under the OPLS3 force field using a dielectric constant value equivalent to the solvent that was used for the NMR measurements (acetone, $\varepsilon=20.7$ ). No bond restrains were applied, and all conformations within $12 \mathrm{~kJ}$. $\mathrm{mol}^{-1}$ of the lowest energy structure were saved for further analysis.

4.6.2. $p K_{a}$ Calculations. Prediction of $\mathrm{p} K_{\mathrm{a}}$ values was undertaken by quantum mechanical calculations in solution phase (water) using selected conformations for each molecule as the input. ${ }^{20}$ A first step of geometry optimization of both of the protonated and nonprotonated forms of each molecule were carried out using the B3LYP functional and 6-31G* basis set. Next, single-point calculations were performed in solution and gas phases at the B3LYP/cc-pVTZ level of theory using the PBF implicit solvation model for evaluation of the solvation energies. Finally, the resultant solvation energies were corrected by a set of empirical parameters as implemented in the software Jaguar.

4.6.3. Docking and Binding Energy Calculations. The Glide software package as implemented within the Schrodinger suite was used to propose binding modes of dragmacidins 1-5 to the catalytic subunit of PP1.32,33 Hence, the protein file was prepared using the coordinates of the PP1-okadaic acid complex (1JK7) after ligand removal. ${ }^{18}$ The comparison between the different crystallographic structures available for PP1 showed only small differences in the protein structure and a conserved water molecule coordinated with metal ions. Therefore, this water molecule was used in our calculations. The Quantum Mechanics Polarized Ligand Docking protocol as implemented in the Glide software was used as follows: an initial rigid receptor docking was performed generating initial charges with a semiempirical method and using the XP (extra precision) mode. Top five poses were used to derive partial atomic charges induced by the protein using electrostatic potential fitting using the accurate option $\left(6-31 G^{*} /\right.$ LACVP* basis set with the B3LYP functional). Finally, the ligands including the new charges were redocked using XP mode, and a maximum of 10 poses of each were saved. Calculations were performed using both ionized and nonionized states for all ligands. The docking area was set around the active site.

MM-GBSA calculations were undertaken using Prime as implemented within the Schrodinger suite. QM charges and positions for all ligands obtained from the docking calculations were used. Residues within a distance of $3.0 \AA$ of the ligands were considered as flexible, and an implicit VSGB2.0 solvation model was used for the calculations. The MM-GBSA protocol included receptor, ligand, and receptor-ligand complex minimizations followed by energy calculations of ligands and receptor extracted from optimized receptor-ligand complex. The resultant binding poses were ranked on the basis of their binding free energies. 


\section{ASSOCIATED CONTENT}

\section{S Supporting Information}

The Supporting Information is available free of charge on the ACS Publications website at DOI: 10.1021/acsomega.7b01786.

$1 D$ and 2D NMR, HRESIMS, and UV and IR of dragmacidins I and J (1-2); HRESIMS, UV, and IR for 3-5; and details of biological evaluation (PDF)

\section{AUTHOR INFORMATION}

\section{Corresponding Authors}

*E-mail: adaranas@ull.es (A.H.D.).

*E-mail: mperez@pharmamar.com (M.P.).

\section{ORCID}

Juan Fernando Martínez Leal: 0000-0002-7538-0875 Antonio Hernández Daranas: 0000-0001-8376-7941

\section{Notes}

The authors declare no competing financial interest.

\section{ACKNOWLEDGMENTS}

We gratefully acknowledge the help of our PharmaMar colleagues, C. de Eguilior for collecting the sponge sample, S. Bueno for determining the sponge taxonomy, G. Benedit and R. Sánchez for their valuable technical assistance, S. Munt for revision of the manuscript, and R. Fernández for the support received. PharmaMar also thanks P. J. Ruysenaars, The Pemba Channel Fishing Club, Shimoni (Kenya), and the Ministry of Livestock and Fisheries, Department of Fisheries and Marine Resources Pemba (Tanzania).

\section{REFERENCES}

(1) Shen, B. A new golden age of natural products drug discovery. Cell 2015, 163, 1297-1300.

(2) Newman, D. J.; Cragg, G. M. Natural products as sources of new drugs from 1981 to 2014. J. Nat. Prod. 2016, 79, 629-661.

(3) Tsujii, S.; Rinehart, K. L.; Gunasekera, S. P.; Kashman, Y.; Cross, S. S.; Lui, M. S.; Pomponi, S. A.; Diaz, M. C. Topsentin, bromotopsentin, and dihydrodeoxybromotopsentin: antiviral and antitumor bis(indolyl)imidazoles from Caribbean deep-sea sponges of the family Halichondriidae. Structural and synthetic studies. J. Org. Chem. 1988, 53, 5446-5453.

(4) Bao, B.; Sun, Q.; Yao, X.; Hong, J.; Lee, C.-O.; Cho, H. Y.; Jung, $\mathrm{J}$. H. Bisindole alkaloids of the topsentin and hamacanthin classes from a marine sponge Spongosorites sp. J. Nat. Prod. 2007, 70, 2-8.

(5) Kohmoto, S.; Kashman, Y.; Mcconnell, O. J.; Rinehart, K. L.; Wright, A.; Koehn, F. Dragmacidin, a new cytotoxic bis(indole) alkaloid from a deep water marine sponge, Dragmacidon sp. J. Org. Chem. 1988, 53, 3116-3118.

(6) Morris, S. A.; Andersen, R. J. Brominated bis(indole) alkaloids from the marine sponge Hexadella sp. Tetrahedron 1990, 46, 715-720.

(7) Wright, A. E.; Pomponi, S. A.; Cross, S. S.; McCarthy, P. A new bis-(indole) alkaloid from a deep-water marine sponge of the genus Spongosorites. J. Org. Chem. 1992, 57, 4772-4775.

(8) Hitora, Y.; Takada, K.; Ise, Y.; Okada, S.; Matsunaga, S. Dragmacidins $\mathrm{G}$ and $\mathrm{H}$, bisindole alkaloids tethered by a guanidino ethylthiopyrazine moiety, from a Lipastrotethya sp. marine sponge. $J$. Nat. Prod. 2016, 79, 2973-2976.

(9) Fahy, E.; Potts, B. C. M.; Faulkner, D. J.; Smith, K. 6Bromotryptamine derivatives from the gulf of California tunicate Didemnum candidum. J. Nat. Prod. 1991, 54, 564-569.

(10) Oh, K.-B.; Mar, W.; Kim, S.; Kim, J.-Y.; Lee, T.-H.; Kim, J.-G.; Shin, D.; Sim, C. J.; Shin, J. Antimicrobial activity and cytotoxicity of bis(indole) alkaloids from the sponge Spongosorites sp. Biol. Pharm. Bull. 2006, 29, 570-573.
(11) Phife, D. W.; Ramos, R. A.; Feng, M.; King, I.; Gunasekera, S. P.; Wright, A.; Patel, M.; Pachter, J. A.; Coval, S. J. Marine sponge bis(indole) alkaloids that displace ligand binding to $\alpha 1$ adrenergic receptors. Bioorg. Med. Chem. Lett. 1996, 6, 2103-2106.

(12) Capon, R. J.; Rooney, F.; Murray, L. M.; Collins, E.; Sim, A. T. R.; Rostas, J. A. P.; Butler, M. S.; Carroll, A. R. Dragmacidins: new protein phosphatase inhibitors from a southern australian deep-water marine sponge, Spongosorites sp. J. Nat. Prod. 1998, 61, 660-662.

(13) Longley, R. E.; Beach, V.; Isbrucker, R. A.; Wright, A. E. U.S. patent 6,087,363; July 11, 2000.

(14) Alvarado, S.; Roberts, B. F.; Wright, A. E.; Chakrabarti, D. The bis(indolyl)imidazole alkaloid nortopsentin A exhibits antiplasmodial activity. Antimicrob. Agents Chemother. 2013, 57, 2362-2364.

(15) Yang, C.-G.; Wang, J.; Tang, X.-X.; Jiang, B. Asymmetric aminohydroxylation of vinyl indoles: a short enantioselective synthesis of the bisindole alkaloids dihydrohamacanthin $\mathrm{A}$ and dragmacidin $\mathrm{A}$. Tetrahedron: Asymmetry 2002, 13, 383-394.

(16) Whitlock, C. R.; Cava, M. P. A total synthesis of dragmacidin B. Tetrahedron Lett. 1994, 35, 371-374.

(17) Miyake, F. Y.; Yakushijin, K.; Horne, D. A. A facile synthesis of Dragmacidin B and 2,5-bis $\left(6^{\prime}\right.$-bromo-3'-indolyl)piperazine. Org. Lett. 2000, 2, 3185-3187.

(18) Sanmartín, C.; Font, M.; Palop, J. Molecular symmetry: a structural property frequently present in new cytotoxic and proapoptotic drugs. Mini-Rev. Med. Chem. 2006, 6, 639-650.

(19) Cruz, P. G.; Daranas, A. H.; Fernández, J. J.; Norte, M. 19-epiokadaic acid, a novel protein phosphatase inhibitor with enhanced selectivity. Org. Lett. 2007, 9, 3045-3048.

(20) Peti, W.; Nairn, A. C.; Page, R. Structural basis for protein phosphatase 1 regulation and specificity. FEBS J. 2013, 280, 596-611.

(21) Bochevarov, A. D.; Watson, M. A.; Greenwood, J. R.; Philipp, D. M. Multiconformation, density functional theory-based $\mathrm{pKa}$ prediction in application to large, flexible organic molecules with diverse functional groups. J. Chem. Theory Comput. 2016, 12, 6001-6019.

(22) Maynes, J. T.; Bateman, K. S.; Cherney, M. M.; Das, A. K.; Luu, H. A.; Holmes, C. F. B.; James, M. N. G. Crystal structure of the tumor-promoter okadaic acid bound to protein phosphatase-1. J. Biol. Chem. 2001, 276, 44078-44082.

(23) Maynes, J. T.; Luu, H. A.; Cherney, M. M.; Andersen, R. J.; Williams, D.; Holmes, C. F. B.; James, M. N. G. Crystal structures of protein phosphatase-1 bound to motuporin and dihydromicrocystin-la: elucidation of the mechanism of enzyme inhibition by cyanobacterial toxins. J. Mol. Biol. 2006, 356, 111-120.

(24) Kita, A.; Matsunaga, S.; Takai, A.; Kataiwa, H.; Wakimoto, T.; Fusetani, N.; Isobe, M.; Miki, K. Crystal structure of the complex between calyculin A and the catalytic subunit of protein phosphatase 1 . Structure 2002, 10, 715-724.

(25) Kelker, M. S.; Page, R.; Peti, W. Crystal structures of protein phosphatase- 1 bound to nodularin- $\mathrm{R}$ and tautomycin: a novel scaffold for structure-based drug design of serine/threonine phosphatase inhibitors. J. Mol. Biol. 2009, 385, 11-21.

(26) Cruz, P. G.; Fernández, J. J.; Norte, M.; Daranas, A. H. Belizeanic acid: a potent protein phosphatase 1 inhibitor belonging to the okadaic acid class, with an unusual skeleton. Chem.-Eur. J. 2008, $14,6948-6956$.

(27) Napolitano, J. G.; Norte, M.; Fernández, J. J.; Daranas, A. H. Corozalic acid: a key okadaic acid biosynthetic precursor with phosphatase inhibition activity. Chem.-Eur. J. 2010, 16, 1157611579 .

(28) Khandelwal, A.; Lukacova, V.; Comez, D.; Kroll, D. M.; Raha, S.; Balaz, S. A combination of docking, $\mathrm{qm} / \mathrm{mm}$ methods, and $\mathrm{md}$ simulation for binding affinity estimation of metalloprotein ligands. $J$. Med. Chem. 2005, 48, 5437-5447.

(29) Cho, A. E.; Rinaldo, D. Extension of QM/MM docking and its applications to metalloproteins. J. Comput. Chem. 2009, 30, 26092616.

(30) Genheden, S.; Ryde, U. The MM/PBSA and MM/GBSA methods to estimate ligand-binding affinities. Expert Opin. Drug Discov. 2015, 10, 449-461. 
(31) Schrödinger Release 2016-2; Schrödinger, LLC: New York, NY, 2016.

(32) Trott, O.; Olson, A. J. AutoDock Vina: improving the speed and accuracy of docking with a new scoring function, efficient optimization and multithreading. J. Comput. Chem. 2010, 31, 455-461.

(33) Dallakyan, S.; Olson, A. J. Small-molecule library screening by docking with PyRx. Chemical Biology; Methods in Molecular Biology; Springer, 2015; Vol. 1263, pp 243-250. 